\title{
Sustaining the use of Positive Education coping skills to meet the challenges of the emerging adulthood period
}

\author{
Nina Stevanovic · Erin Hoare · Vicki Mckenzie · Meredith O'Connor
}

\begin{abstract}
The Positive Education approach is a whole-school program implemented in primary and secondary school settings that aims to equip students with effective coping skills. During the transition to adulthood (often termed "emerging adulthood"), young people encounter a variety of challenges and are expected to draw on their own resources to cope. The current qualitative study aimed to provide initial insights into whether young people exposed to Positive Education training at school continue to use these coping strategies during emerging adulthood, when they have left the school setting. Twenty-one graduates (9 male, 12 female, $18-19$ years old) of a Victorian independent school who had received four years of explicit Positive Education training completed semi-structured interviews via telephone. The interviews focused on the challenges the participants encountered after leaving school, skills they used to cope with those challenges, and factors that affected their use of Positive Education skills. Qualitative analysis showed that all participants were using skills that are taught within Positive Education to some extent, once they had left the secondary school setting. Young people identified a range of barriers and enablers to their continued use of these skills beyond the school setting. The findings suggest that Positive Education training may be helpful in preparing young people for the challenges of the emerging adulthood period. However, further program development is needed to promote the sustained use of these skills.
\end{abstract}

Keywords: Positive Education, emerging adulthood, qualitative study

\section{Introduction}

As young people develop from adolescence into the early stages of adulthood, the institutional structures around them are reduced and parental influences start to become less significant. As a result, young people are increasingly required to draw on their own resources to cope (Côté, 2006). While this brings many new freedoms, it also brings about new challenges (Harlow, Mitchell, Fitts, \& Saxon, 1999). For some young people, this can be overwhelming, and rates of diagnosable mental disorders during the period of transition between childhood and adulthood can reach 50\% (McGorry, 2013).

Positive Education (PE) is a recently developed approach that seeks to promote positive mental health in adolescence (Norrish, Williams, O'Connor, \& Robinson, 2013), and may provide an opportunity to upskill adolescents in preparation for this challenging transition. PE has been implemented as a whole-school approach, including individual, community and leadership level initiatives, aiming to teach young people strategies and skills to improve their wellbeing and resilience. PE aims to both benefit young people at that time and in preparation for challenges they are likely to encounter once they leave school (O'Connor et al., 2014).

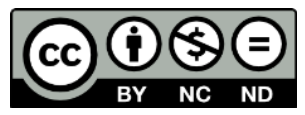

Copyright belongs to the author(s) www.internationaljournalofwellbeing.org 
While evaluations of PE are promising in terms of its short-term benefits (Waters, 2012), there is currently a dearth of information about how PE skills permeate beyond the school setting, and whether use of these skills is sustained into adulthood. The current study presents a small-scale initiative to provide some insights into how PE skills might be used during emerging adulthood to facilitate the young adult's effective coping.

\subsection{Challenges and opportunities in the emerging adulthood period}

A significant societal shift observed over the past few decades in many Western industrialised countries is the later achievement of traditional adult milestones. For example, in Australia, the average age of marriage and birth of first child has increased by over seven years over the past four decades (Australian Bureau of Statistics, 2016; Hayes, Qu, Weston, \& Gray, 2010). The concept of "emerging adulthood" (EA) has been used to describe this prolongation of the transition from adolescence to adulthood (Arnett, 2000). Usually applied to the period from 1825 years, this period is characterised by significant developments in identity, autonomy, responsibility for oneself, and financial independence. During this time, many young people enter tertiary education, but others travel or enter the workforce, with the result that emerging adults have a very heterogeneous demographic profile.

During EA, young people move from the relatively structured and contained role at school to a relative lack of structure or institutional support, where new pathways may be forged as new opportunities and experiences arise (Masten, Obradović, \& Burt, 2006; Schulenberg, Sameroff, \& Cicchetti, 2004). While for some this provides the opportunity to change direction towards a more positive course, for others this presents a potentially overwhelming challenge (Arnett, 2006; Schulenberg \& Zarrett, 2006). Consistent with this, relatively high incidences of problem outcomes are observed in this stage of life. For example, emerging adults have a higher incidence of depression than other age groups (Kessler \& Walters, 1998). Looking to opportunities for intervention to promote strong mental health outcomes prior to young people entering the EA period is vital, in order to allow young people to build strong capacities and skills so that they are ready and equipped to tackle the challenges of the EA period (Eccles, Templeton, Barber, \& Stone, 2003). In this regard, primary and secondary schools are uniquely placed to deliver positive mental health interventions to wide populations (Seligman, Ernst, Gillham, Reivich, \& Linkins, 2009), in order to promote healthy developmental pathways into EA.

\subsection{Positive Education}

School-based Positive Education programs provide one such approach to developing skills prior to the EA period. PE is a framework that proposes that skills for positive adaptation and resilience can be explicitly taught and developed within educational settings, in both primary and secondary schools (Norrish et al., 2013). This focus on wellbeing within schools is designed to supplement traditional academic learning (Seligman et al., 2009), and to provide students with wellbeing skills that remain valuable over the life course.

Geelong Grammar School (GGS) is an independent, Anglican, co-educational, boarding and day school located across four campuses in Victoria, Australia. In 2008, following a six-month invited visit from Professor Martin Seligman, alongside other international experts, GGS developed and implemented PE as a whole-school approach (Norrish, et al., 2013). The approach is based on six broad and interrelated wellbeing domains including: positive emotion, engagement, accomplishment, purpose, relationships and health, underpinned by a focus on character strengths. The character strengths are defined as ubiquitous personality traits with 
moral value, and harnessing and fostering such strengths is assumed to allow an individual to flourish and function optimally.

The whole-school approach incorporates the wellbeing domains into the school at multilevels, referred to in its catch-line as the four processes of Learn it, Live it, Teach it, Embed it.

The Learn it process is sharing opportunities as a whole-school community to understand and engage with the science of wellbeing. Staff participate in multi-day training programs to introduce PE, and to develop their application and potential to use skills day-to-day in their personal and professional lives. Additional "top-up" workshops are available for all staff to maintain and further understand their practice of PE.

The Live it process refers to enacting evidence-based wellbeing practices in an individual's unique way in their own lives. Staff are encouraged to become authentic role models for the students through living the skills taught within PE. For example, staff are encouraged to harness their character strengths in difficult situations, actively practise mindfulness and gratitude, foster strong positive relationships with family, friends and colleagues, nurture a healthy lifestyle, and contribute to meaningful communities and projects. It is expected that by endeavouring to live by the principles of Pos Ed, an individual's own wellbeing and the wellbeing of others will be supported.

The Teach it process refers to providing students with dedicated time to discover and explore each of the key domains of wellbeing. Students from Years 5 through Year 10 attend regular timetabled lessons in PE, which cover a range of skills, knowledge and mindsets pertaining to the components of the GGS model for PE. Originally based on the Penn Resiliency Program (Brunwasser, Gillham, \& Kim, 2009) and the Strath Haven Program (Seligman et al., 2009), the PE classes include topics such as: active constructive responding, optimism, mindfulness, perspective of challenges, creativity, and involvement in community service. A full list of components and skills taught in the GGS model of PE has been published elsewhere (Norrish et al., 2013; O'Connor \& Cameron, 2017).

The Embed it process refers to the adopting of long-term school-wide policies and practices which support and nurture wellbeing within individuals and within the community. Examples of such changes include character strengths being central to assemblies or chapel services, visual displays of gratitude, and random acts of kindness. Efforts to engage all relevant stakeholders in the school community, such as through offering residential training programs in PE, further support the whole-school approach in embedding PE.

Whilst the GGS model has been developed based on a growing body of evidence for how to best promote flourishing, some important considerations remain, relating to the long-term effectiveness of the program. A three-year quasi-experimental longitudinal study of GGS students and other Australian school students has recently been completed, which will assist in assessing the effectiveness of PE over time. Given that the PE model aims to provide students with skills to support wellbeing across the lifespan, the impact of PE beyond school years is of considerable interest. Several studies have found support for PE interventions aimed at improving wellbeing in the short term (Vella-Brodrick, Rickard, \& Chin, 2014). However, there is a need for research to determine the extent to which skills are sustained over the longer term or their relevance to the specific challenges of students when they leave the school.

\subsection{Sustaining behavioural change over time}

While there is not yet evidence specifically on the sustained use of coping strategies in relation to PE, insights from other areas of research do, however, suggest that maintaining health behaviour change over time is challenging. For example, evidence from public health literature 
suggests that while the antecedents and health consequences of non-communicable diseases are well-known, interventions leading to sustained health behavioural change to prevent such diseases have shown limited effectiveness (World Health Organization, 2014).

Despite challenges, there is evidence to suggest specific factors increase the likelihood of sustained behavioural change. A synthesis of research completed by the National Institutes of Health and the Health Maintenance Consortium summarised the evidence for sustaining behavioural change in relation to a broad range of health and wellbeing outcomes (Ory, Lee Smith, Mier, \& Wernicke, 2010). Empirical findings found the strongest effects in terms of behavioural change are usually observed in the one or two years closest to the active intervention, and this was particularly strong with additional maintenance treatment or intervention boosters. Sustained behavioural change was observed in interventions that included environmental or organisational level changes, and also those that leveraged naturally occurring intervention opportunities.

\subsection{The current study}

To fully capitalise on the potential of PE, it is important to investigate the extent to which Positive Education skills continue to be used by students after experiencing the program during their school years and the factors that may contribute to their sustainability.

The current study aimed to address the following research questions:

1) What key challenges did participants report facing during their first years after leaving school?

2) Did recently graduated students use Positive Education skills to cope with challenges that arose in emerging adulthood? If so, which skills did they use?

3) What factors were reported to a) impede or b) promote the use of Positive Education skills during the post-school transition?

\section{Methods}

\subsection{Design}

The study was a qualitative exploratory study designed to examine the extent to which PE skills were used in EA. Outcomes were measured during 2015 through semi-structured interviews via telephone. A phenomenological approach was adopted to obtain rich information regarding PE skill use through participant descriptions of lived experiences. This study received ethics approval from the Melbourne Graduate School of Education Human Ethics Committee.

\subsection{Participants}

117 Geelong Grammar School graduates were invited to participate in the study. Twenty-six participants responded to the invitation, 21 individuals consented to participate (12 females, nine males), and the remaining five were unable to participate due to time constraints. Demographic data of participants is illustrated in Table 1. Participants ranged from 18 to 19 years old and all had graduated within 12 months prior to the interview. Nineteen participants indicated that they were enrolled in tertiary studies. Approximately half of the participants were residing within college accommodation (48\%), one-third were residing within the family home (33\%), and 19\% were renting in independent accommodation. Geelong Grammar graduates enrolled after 2012 were excluded from the study $(7 \%)$ to ensure that all participants had been exposed to explicit teaching in PE. Exclusion criteria were also applied to participants for whom contact details were not available (9\%). 
Table 1. Participant demographic data

\begin{tabular}{llrl}
\hline Demographic Factors & & N & \% \\
\hline Age & 18 & 9 & 43 \\
Gender & 19 & 12 & 57 \\
\multirow{3}{*}{ Vocational status } & Male & 9 & 43 \\
& Female & 12 & 57 \\
Residential status & Tertiary studies & 19 & 90 \\
& Other & 2 & 10 \\
& Family home & 7 & 33 \\
& College & 10 & 48 \\
\hline
\end{tabular}

\subsection{Measures}

A semi-structured interview schedule containing five demographic questions and 10 open-ended interview questions was developed for use in the current study. Demographic questions pertained to participant gender, age, living arrangements, vocational status and years enrolled at GGS. The open-ended questions focused on participant use of PE skills after secondary school (Table 2). A script was used for each interview and all participants received a reminder of the key PE skills targeted by the GGS curriculum at the commencement of the interview.

Table 2. Interview schedule pertaining to participant use of Positive Education skills

\section{Interview Questions}

1. Can you tell me your thoughts overall on how helpful Positive Education skills have been during these last few months since finishing school? Can you give me a specific example of when you used that skill?

2. What has encouraged you to use Positive Education skills since finishing high school?

3. What has got in the way of using Positive Education skills since finishing school?

4. Tell me about the main challenges you've encountered since leaving high school. Have any Positive Education skills mentioned before or any others helped you to tackle this issue?

5. Are there any strategies apart from those you learned in Positive Education that have been helping you to cope with these challenges? For example, are you involved in yoga, meditation, wellbeing workshops and so on?

6. Have you engaged in extracurricular activities since finishing high school? What are they?

7. How have Positive Education skills contributed to your engagement in extracurricular activities since leaving school?

8. Have you engaged in any activities that have helped to improve your physical health since finishing high school? Physical health includes physical strength, flexibility, endurance, nutrient intake or high-quality sleep.

9. How have Positive Education skills contributed to your physical health since finishing high school?

10. Can you think of any helpful Positive Education supports that schools could offer to young people once they've graduated? For example, things like online resources. 


\subsection{Procedure}

Participant contact details were obtained with permission from GGS. Participants were contacted via email and were provided with a consent form and plain language statement outlining the research aims, significance, procedures and confidentiality protocol. Participants were informed that the study aimed to investigate whether former GGS students use PE skills after secondary school. Participants indicated via email their desire to participate and indicated a suitable time to conduct a telephone interview. Participants who did not respond to the initial email were contacted for a second time via email to confirm their attitude to follow-up regarding participation interest.

Informed consent was obtained from each participant via verbal agreement and all participants were interviewed using the same semi-structured interview format. Upon completion of the interview, all participants were provided with an opportunity to receive a $\$ 40$ gift voucher for the local shopping centre to compensate for their time.

All interviews were conducted by one researcher (NS) via telephone. The duration of the telephone interviews was approximately 20 - 35 minutes per participant and was determined by the volume of information provided by the participant. All interviews were audiotaped with the participant's permission and participants were assured of confidentiality.

\subsection{Data analysis}

Data was analysed via an inductive thematic approach, commonly used in qualitative research. Thematic analysis is the process of identifying, analysing and interpreting patterns within data (Braun \& Clarke, 2006) and allows for an in-depth search for themes and patterns across an entire data set. The thematic approach does not require pre-existing theoretical frameworks to guide the data and is flexible in allowing for a relatively objective process in analysis. The inductive method of analysis means that the themes are strongly linked to the data without trying to fit the data into the researcher's analytic preconceptions, thus minimising bias (Braun \& Clarke, 2006).

Each interview was transcribed verbatim (NS) in order to establish familiarisation with the data. Initial ideas, thoughts and observations regarding commonalities and insights were noted. The software program NVivo was used to code and classify sections of the text that appeared relevant and contributed to meeting the research aims. As the interviews were semi-structured and some participant responses ambiguous, the codes were established by one researcher, primarily due to having in-depth knowledge of the subject matter (Campbell, Quincy, Osserman, \& Pedersen, 2013).

Data that corresponded to specific codes was analysed and categorised into overarching themes, and mind maps were developed to further understand the connections between codes and themes. Finally, research aims were addressed by formulating a detailed analysis of the extracted themes.

\section{Results}

There were three main themes extracted from the data. These were: 1) challenges encountered after leaving school, 2) coping strategies used to mitigate challenges and 3) factors that were attributed to the way in which PE skills were used.

\subsection{Key challenges encountered during emerging adulthood}

The three key challenges that participants reported most frequently encountering after leaving school were: changing friendships, academic expectations and reduced structure. In relation to 
changing friendships, participants identified difficulty in establishing new friendships but also in maintaining old friendships. The challenge of establishing new friendships was primarily associated with daunting thoughts about the task of forming friendships (e.g., "There's a lot of that nervousness, like, oh, what if I don't make friends or meet people?" "I often get scared that I'm losing some of my friends").

Furthermore, uncertainty about the changes in academic expectations as well as an increase in difficulty and volume of set tasks appeared challenging for the participants (e.g., "Difficulty of work is much higher than at high school," "I found it [university] quite a shock because it feels like there's not much work and you're on top of it but there's actually a lot of content that you need to be up with").

Alongside challenges associated with tertiary education, participants also identified a lack of structure and guidance as a challenge that primarily coincided with an increase in autonomy. Freedom to make their own decisions and establish a routine appeared daunting (e.g., "Coming out of that [school] and doing my course [by] correspondence means I can do pretty much what I want when I want, which is both good and daunting because you have to set your own goals and stick to them").

\subsection{Positive Education coping strategies used to mitigate challenges}

Although the vast majority of participants reported using PE skills to some extent, the majority of participants $(71 \%)$ indicated that they used the skills without explicitly thinking of them as deriving from the PE program at school (Figure 1).

Figure 1. Percentage of participants reporting use of specific PE skills

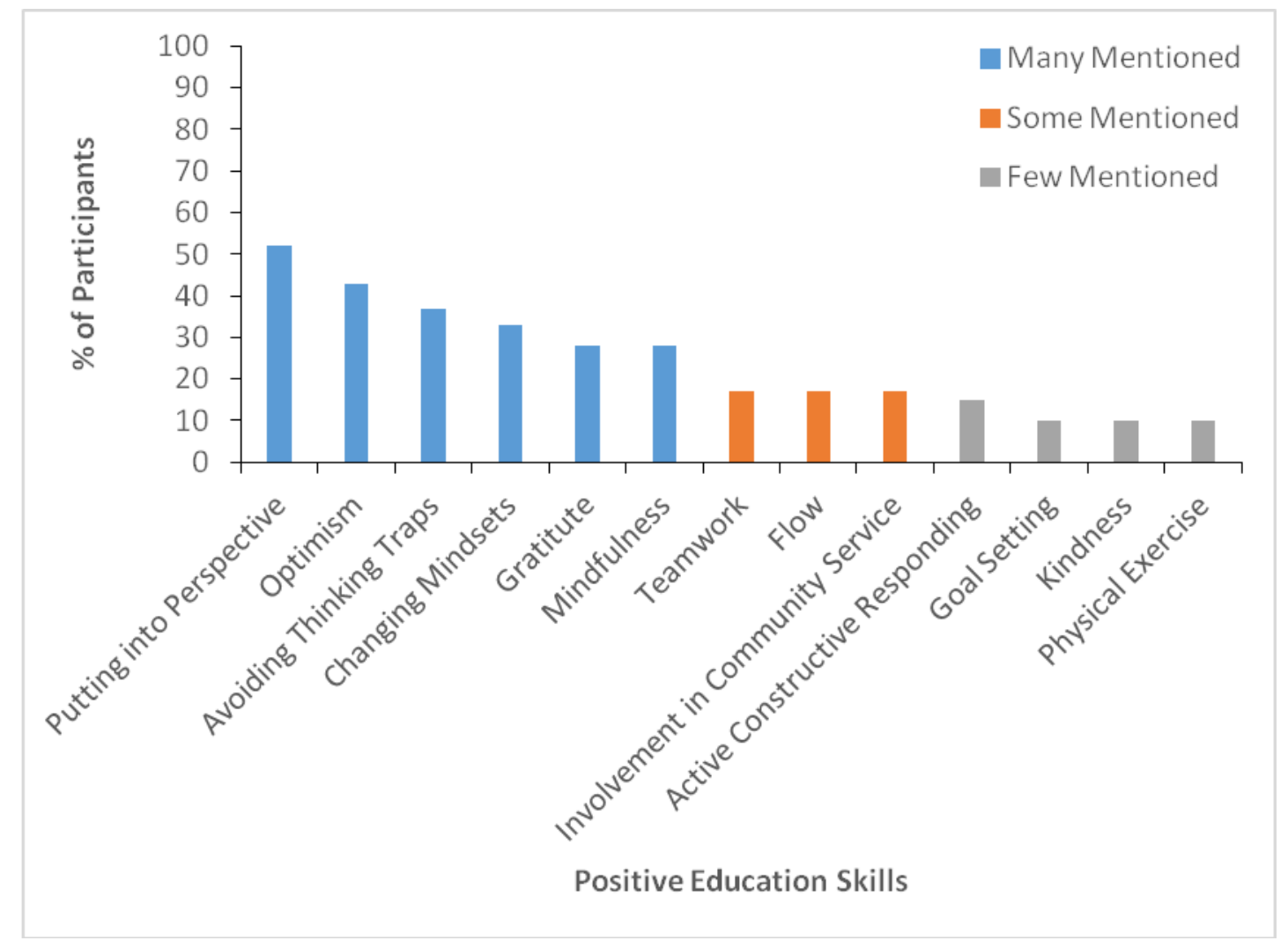


Some recognised that they had been using the skills unconsciously (e.g., "I think that it has been subconscious in structuring my life but I do think it has been reasonably helpful in that sense, even though I haven't been explicitly thinking about different elements of Pos Ed").

However, others had difficulty identifying specific learning from PE. For example, the majority of participants had difficulty differentiating between the influence of PE, GGS, and their own personalities in the use of coping strategies (e.g., "Things that we learnt in PE were things that my parents always taught me. So I think, yes, I do use them but I don't think it's necessarily due to being at Geelong Grammar").

The majority of participants identified use of the skill of putting into perspective, and avoiding thinking traps (Figure 1), echoing the resilience taught within the PE model (Norrish et al., 2013). Resilience in the GGS model refers to the capacity to adapt and develop when faced with challenges (Masten, 2001; Norrish et al., 2013). Avoidance of thinking traps appeared to be a precursor to being able to employ effective coping strategies, such as putting things into perspective. For example, participants appeared to identify negative thoughts but were able to avoid rumination and catastrophising by perceiving a variety of positive perspectives, although they did not tend to explicitly recognise that they were using PE skills to mitigate the challenges (e.g., "Like putting things into perspective just like little things at the time. It's like this is so hard doing this at uni but it's like one day of this and you'll be fine").

Furthermore, the participants often used the skill of putting things into perspective in response to experiences of conflict with peers and in mitigating university challenges. For example, the participants reported attempting to understand others' perspectives and looking for positives within difficult situations (e.g., "More recently it was what my results were going to be like for uni but that was all. Fear of the unknown and fear of what could happen. Even then I wasn't that stressed because I knew that everything would work out. It wasn't life or death"), whereas avoidance of thinking traps was associated with an awareness of negative emotional states and avoidance of ruminating and catastrophising (e.g., "I've always been an optimistic character and living on my own you don't really want to spiral down into a negative mindset where everything you do and think is negative, so, yeah, I guess that's pretty important").

Participants also reported using strategies such as optimism and gratitude that reflect the positive emotions component within the PE model (Norrish et al., 2013; O'Connor \& Cameron, 2017). Positive emotion reflects students' capacities to anticipate, initiate, experience, prolong, and build positive emotional experiences (Norrish et al., 2013). Gratitude refers to acts or displays of appreciation toward others, and optimism refers to hopefulness and confidence about future successes. Optimism also appeared to assist participants to put things into perspective and avoid thinking traps. For example, participants who reported employing strategies to perceive challenges from a variety of perspectives, tended to employ strategies such as looking to the positives within a negative situation, and, in turn, were able to avoid thinking traps. In addition, participant use of optimism related to persistence and perseverance in tasks despite experiences of challenges (e.g., "So I had to keep at it and keep thinking it's a good opportunity and everything will work out to get through the first few months at uni").

Furthermore, the participants were able to explicitly state their use of gratitude and clearly identify how they used the skill (e.g., "Well, since I finished school, I started doing Project 365. I don't know if you know what that is but that's when you take a photo every day of something you're grateful for. So I did that the day after I finished school because I wanted to keep something up and I wanted to make sure I'm doing something interesting every day and being aware of what I'm grateful for, every day"). 
The majority of participants made reference to mindfulness, however, only a portion of the participants reported using the skill to mitigate challenges (Figure 1). Furthermore, participants who mentioned mindfulness appeared to either have positive or negative perceptions of mindfulness. Of the portion of participants who exhibited positive perceptions of mindfulness, the majority reported explicitly employing meditation as a strategy to relax and settle their thoughts (e.g., "The school would hold meditation sessions every now and then for year $12 \mathrm{~s}$ to take their minds of all the stress of exams and take a break from reality and so I've been doing that a few times a week during the last month or so, which I think has really helped me").

\subsection{Factors affecting use of Positive Education skills}

\subsubsection{Facilitating factors}

Participants identified several facilitating factors that contributed to their use of PE skills postsecondary school. These primarily included correspondence with values and the influence of secondary school teachers (Figure 2).

\section{Figure 2. Percentage of participants and specific encouraging factors identified}

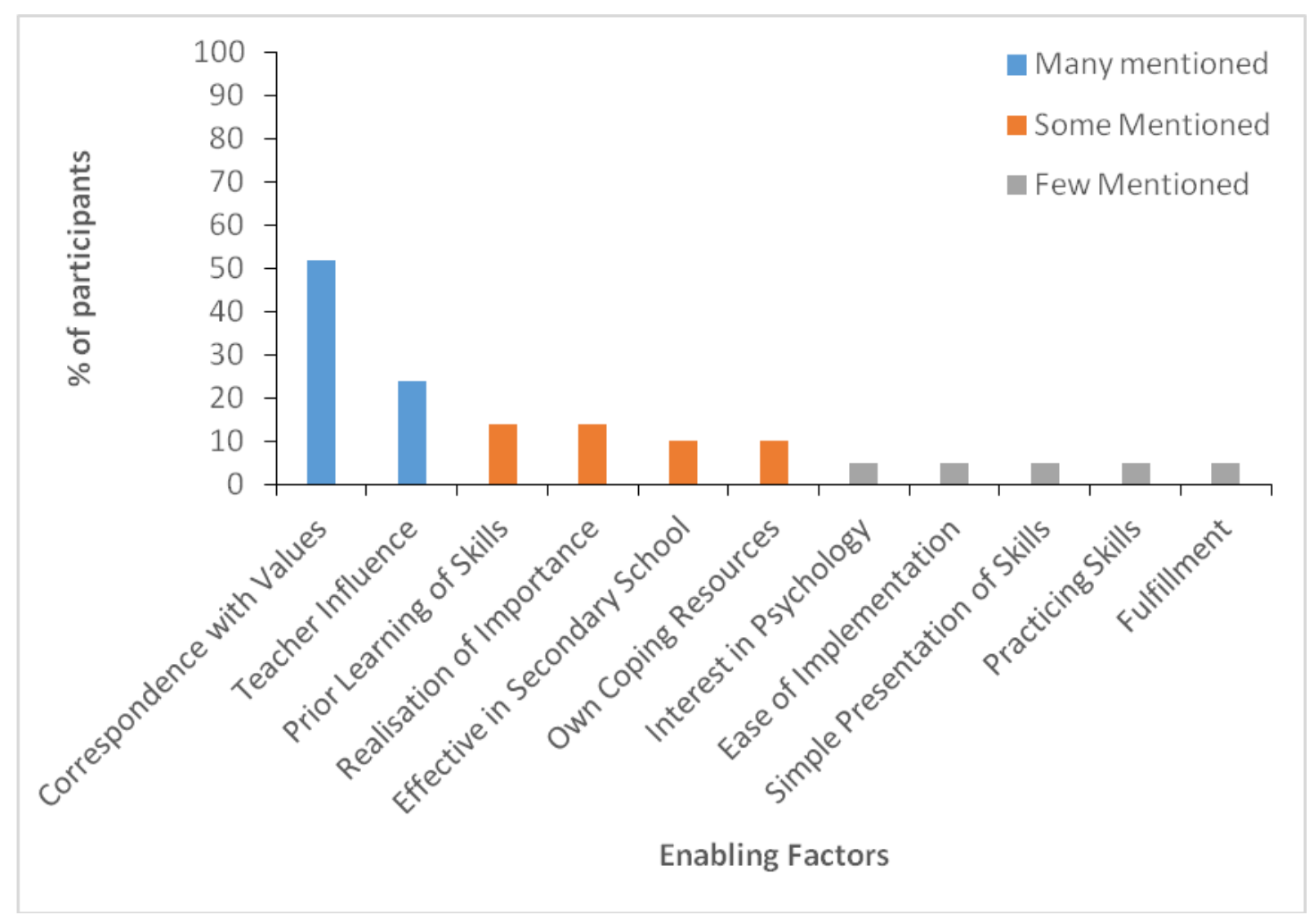

Correspondence with values. Participants who identified PE skills as corresponding with their values reported that PE was in line with either familial or personal values. For example, parental beliefs regarding the efficacy of PE appeared to influence participant valuing of PE skills. In addition, participants appeared to value PE skills if they perceived them to be effective coping mechanisms and ways in which they had previously "approached" challenging situations (e.g., "probably my mum, seeing as she is on board with all that Pos Ed sort of stuff as well," "reinforcement of the way I sort of saw things anyway").

Influence of teachers. Teacher influence also contributed to an establishment of positive associations with PE skills. Hence, participants perceived teacher encouragement to use PE skills in secondary school as helpful in continuing to use the skills post-secondary school (e.g., "I think 
the teachers definitely endorsed the Pos Ed and through that, it kind of radiated through the whole system. Which is good. Like I never practiced in the mediation side as much or I didn't constantly really think about PE, it just kind of happened naturally through the teachers and the whole community").

\subsubsection{Impeding factors}

The majority of participants identified several impeding factors that affected their use of PE skills after secondary school. These primarily included lack of perceived relevance, non-valuing skills, lack of understanding of purpose, lack of external reinforcement, and the theoretical rather than experiential method of teaching (Figure 3).

Figure 3. Percentage of participants and specific impeding factors identified

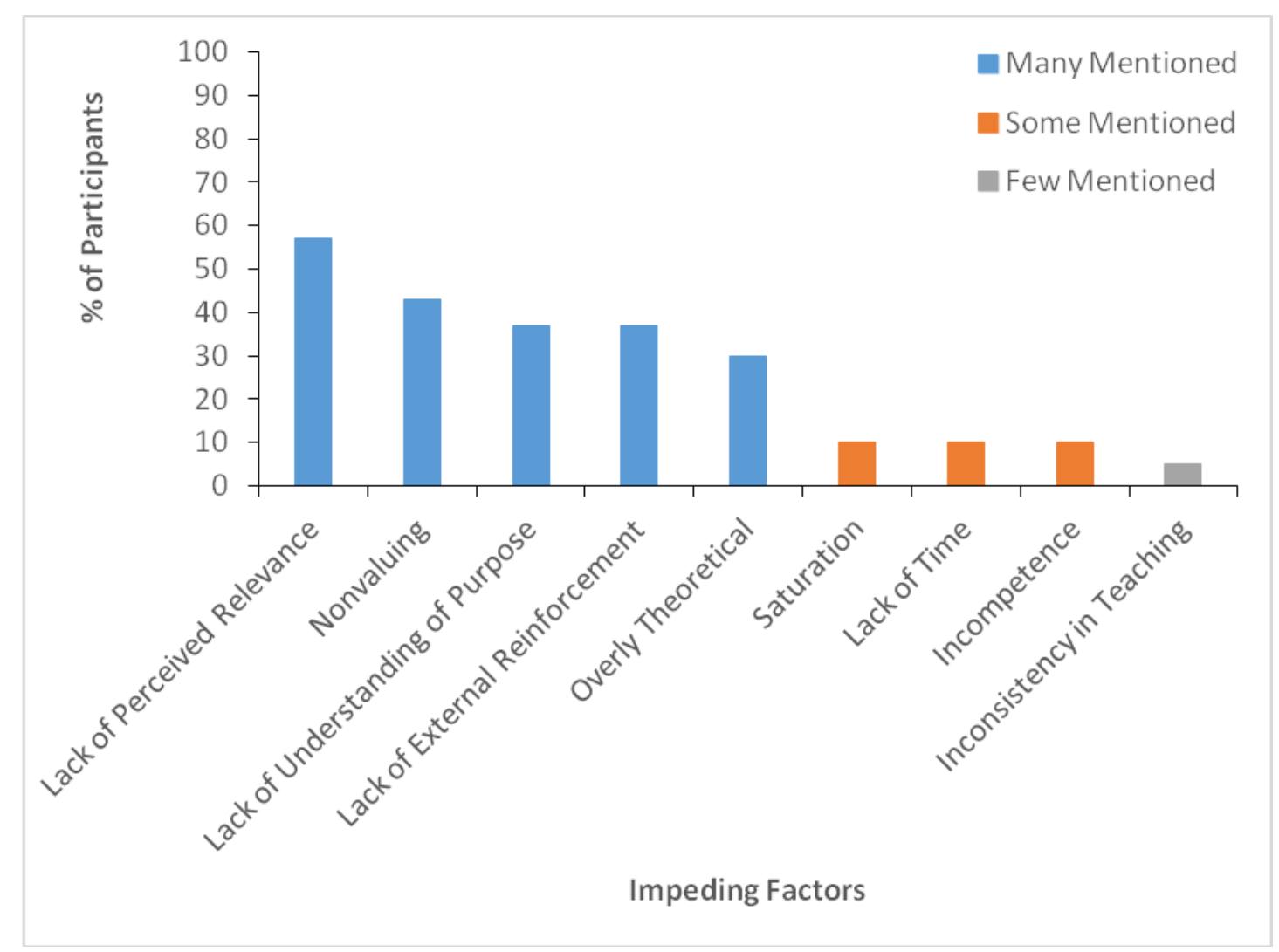

Lack of perceived relevance to current challenges. The majority of participants perceived that PE skills were more relevant during secondary school, primarily due to tailoring the skills to mitigate study challenges. Thus, participants reported difficulty in applying and generalising skills to mitigate challenges encountered after secondary school (e.g., "I just feel like it was also very tailored to study habits, the way they taught PE," "Most of the examples and the way we talked through PE at school relates very much to what you're doing at school. It makes sense to understanding how it works but learning to apply school outside of that environment can sometimes be more difficult)".

Non-valuing of skills. Furthermore, the majority of participants specifically reported having either negative or positive perceptions of mindfulness, with almost half of the overall sample reporting that they were not using mindfulness as a strategy to mitigate challenges. This was primarily due to a lack of correspondence with personal values (e.g., "I just don't really like the 
quietness and people directing me in the breathing in the muscle relaxation. I'm just deterred from it and I don't know why").

Lack of understanding of the purpose of Positive Education. Some participants felt that PE was vastly encouraged during secondary school but they appeared to lack understanding of the purpose of PE skills. Lack of understanding of the purpose of PE also appeared to relate to a lack of perceived importance of PE skills (e.g., "I guess some of the things felt like a waste of time, like I didn't have time to do them," "I just thought it was a waste of time and I didn't really ummm get involved much when I was at school").

Lack of external reinforcement. Another impeding factor in the use of PE skills appeared to be the lack of cues to remind participants to use PE skills, and encouragement to do so from external sources such as teachers. Lack of external reinforcement was primarily identified as an impeding factor for skills that are not being utilised by the participants (e.g., "Not having constant reminders of the skills or how to use them is probably the biggest challenge," "I just think it's based around the situation. I guess you have to have something that triggers it. I guess not being at school and people at school, you forget about it a bit and it's not exactly there").

Theoretical rather than experiential method of teaching. The participants indicated that they preferred experiential tasks as opposed to learning about theory. They also indicated that their perceptions of the relevance of PE skills were affected by their perceptions of the practicality and applicability of the skills (e.g., "I didn't find that it was practical enough or hands-on enough for me to use the skills. That's why I think that I found the meditation interesting because we actually did that ourselves, whereas the rest was textbook teaching and we were lectured about that stuff and it was removed and not as interactive as it could have been").

\subsubsection{Feedback regarding useful Positive Education resources.}

The majority of participants indicated a desire for resources to be available once they had left school to assist in maintaining PE skills and employing skills to mitigate challenges. Some commonly identified ideas for resources included: establishment of websites, PE newsletters, applications for mobile telephones, and interactive workshops.

\section{Discussion}

This study adopted a phenomenological approach to examine the degree to which recently graduated students from Geelong Grammar School used Positive Education skills, including which skills are predominately used and in what contexts, and to investigate the factors that impede or promote the use of skills. The current study found participants reported experiencing challenges commonly identified in the EA period (e.g., changes in social networks, academic expectations, and a reduction in institutional structure and guidance) (Arnett, 2000) and that they were using PE skills to some extent to cope. Young people identified a range of barriers and enablers to their continued use of these skills beyond the school setting, and these findings hold importance for the further development of PE in relation to the sustainability from adolescence into EA. The findings are representative of a small cohort of respondents, but do provide useful reflections on the way the impact of the program over time can be considered and evaluated.

Challenges faced during emerging adulthood. The respondents raised challenges of changing friendships, academic expectations, and reduced structure, which aligns with previous findings in both Australia and the US. Emerging adults experience significant changes in their environmental contexts (e.g., changes in living arrangements, relocation, transition into tertiary institutions), as well as greater autonomy and opportunities to interact with a variety of peers (Arnett, 2000). Additionally, toward the end of secondary school, adolescents are likely to exert 
increased effort to produce quality work in order to attain entry into desired tertiary education. Consequently, acceptance into a desired tertiary course may be perceived as a major accomplishment for many young people (Vuong, Brown-Welty, \& Tracz, 2010). Young people are thus likely to continue to perceive academic success as important during the EA period, and are likely to experience environmental transitions.

Strategies used to mitigate challenges. Given the challenges that derive from the life-stage issues for this group as they transitioned out of secondary school, use of effective coping strategies could mediate the impact of such stressors (Mahmoud, Staten, Hall, \& Lennie, 2012) and promote resilience. The findings of the current study indicated that PE skills could be useful during EA but many barriers were identified to the continuous use of skills. The participants reported use of resilience skills, and reappraising strategies (i.e., putting things into perspective) once negative emotions began to surface. It has been proposed that strategies that aim to reappraise rather than suppress events that are perceived as challenging may be more beneficial in assisting people to cope more effectively, as they are able to directly focus on resolving the problem (Tugade \& Fredrickson, 2006).

Facilitating factors. Valuing of skills and the positive influences of external sources were identified by the participants as salient in contributing to their motivation to use PE skills to meet challenges during the transition to EA. Valuing of skills primarily appeared to be a function of the correspondence between PE skills and personal characteristics (e.g., coping styles). This finding is worth noting, as coping tends to be more effective when the strategies acquired are part of an individual's personal coping style (Moos \& Holahan, 2003). Hence, when the acquired coping skills align with a person's beliefs and values, individuals are more likely to perceive themselves as efficacious in applying the coping strategies and are more likely to perceive merit in using the coping skills (Moos \& Holahan, 2003). In addition, positive experiences of using PE skills to cope effectively seemed to further strengthen participant self-efficacy in using the skills to mitigate challenges. Moos and Holahan (2003) described this process in terms of a conceptual framework, whereby environmental systems (challenges and resources) and personal systems (coping styles and self-efficacy beliefs) interact with previous experiences of coping to facilitate the execution of coping skills to mitigate challenges and improve wellbeing.

Furthermore, the findings also indicated that participants were motivated to use PE skills due to the influence of teachers who endorsed PE in secondary school. The participants expressed that they had established positive relationships with these teachers and indicated that they were positive role models. Hence, it is likely that the participants also perceived their teachers as models of resilience and coping rather than merely people who delivered PE content. Johnson, Taasoobshirazi, Kestler, and Cordova (2014) found that teachers who were perceived as positive role models of resilience in secondary school were more influential on college students' associations and motivation to employ coping strategies to improve their resilience and wellbeing. Additionally, positive relationships with teachers may have facilitated the establishment of self-efficacy through constant reinforcement of PE skills and perceptions of effective employment of PE skills by the teachers.

Impeding factors. The findings indicated that the participants had difficulty generalising some PE skills to new challenges they encountered after secondary school. It is possible that the participants may have perceived some PE skills as effective in similar circumstances as those encountered during secondary school (e.g., studying) but that their self-efficacy to implement skills diminished once the types of challenges they experienced changed (Eccles \& Wigfield, 2002). Self-efficacy is derived from the expectation that one has the ability to perform necessary skills and that certain behaviours will lead to certain outcomes (Eccles \& Wigfield, 2002). In this 
instance, the participants perceived that they had the ability to acquire skills from PE but lacked confidence in applying such skills to mitigate challenges encountered in EA. This lack of perceived generalisability of skills is likely to affect young people's persistence in using the skills to mitigate challenges beyond secondary school (Eccles \& Wigfield, 2002).

Additionally, in some cases, lack of valuing of skills led to the cessation of using some PE skills to mitigate challenges in EA. Interestingly, many participants identified mindfulness as an unhelpful strategy in dealing with these challenges. There may be several reasons for this finding. In some cases, the participants tended to perceive mindfulness strategies as novel and different to their natural coping styles, hence their lack of value placed on mindfulness may have stemmed from an incongruence with personal values and characteristics (Moos \& Holahan, 2003). Also, mindfulness is a skill that requires explicit and constant practice for a prolonged period of time before it is automatised and the benefits are achieved (Hyland, 2015). Considering that the participants reported mainly using skills that are likely to have produced immediate alleviation of negative emotions (e.g., putting things into perspective, and positive thinking), they may have perceived mindfulness as ineffective, as the benefits were unlikely to have been attained immediately. Hence, lack of correspondence with personal characteristics and lack of attainment of immediate benefits may have affected participant valuing and persistence to use mindfulness strategies.

Furthermore, the participants reported lack of external encouragement as another impeding factor in continuing to use some PE skills to mitigate challenges in EA. This indicates that the use of some PE skills was extrinsically motivated. For example, verbal encouragement from teachers contributed to participant compliance to use PE skills in secondary school. However, once compliance to use the skills was no longer required and verbal encouragement ceased, the participants discontinued their use of PE skills. Although it is possible to sustain motivation extrinsically, if the function of the extrinsic motivation is to exert compliance, or to gain praise or rewards, the individual will likely cease their use of skills once the extrinsic motivator is removed (Ryan \& Deci, 2000a). Additionally, a lack of understanding of the importance and purpose of skills may further exacerbate demotivation to use the skills, particularly once the external motivator is removed (Ryan, 1995). Hence, when the meaning and the purpose of a behaviour is understood, it may become internalised, causing a motivational shift to occur (Ryan \& Deci, 2000b).

The participants also identified that the method of teaching (e.g., theoretical rather than experiential) of PE skills in secondary school was a factor in their motivation to use the skills in EA. In experiential learning, the learner is able to experience, reflect, think and act repetitively within a learning context (Kolb \& Kolb, 2008). People can use their experiences to assist them in formulating conceptualisations of the learning tasks and to directly guide their behaviour. For example, Freire (1993) argued for "problem posing education" in which students are engrossed in the here and now experiences of their lives whereby critical reflection and action are encouraged to improve their lives. It is interesting, however, that a large portion of participants did not tend to value mindfulness in which opportunity was provided for experiential learning. Hence, in order for experiential learning to be effective, it is likely that the skills also need to be valued.

\subsection{Strengths and limitations}

The current study offers valuable insight into the coping mechanisms of young people as they transition into the EA period and face new challenges. The qualitative nature of the current study allowed for extraction of rich information regarding PE skill use and enabled thorough analyses 
of the data. As the concepts and themes under investigation were not pre-determined, the participants were able to openly reflect on their experiences of PE skill use after secondary school. Furthermore, the findings from the current study reflect lived experiences and real life situations in which education had an impact on their development. The semi-structured, open-ended nature of the interview questions also assisted participants to elaborate on their answers in detail.

Although the current study demonstrated several strengths, it is not without limitations. Firstly, it was difficult to generalise the findings to a wider population, as the sample of participants was small and represented young people from a niche, highly resourced boarding school setting. However, as the focus of the study was to investigate the use of PE skills in coping with new challenges encountered in EA, it was essential to select a sample from a school that delivers well-established explicit teaching in PE.

The methodology involved contacting the participants via email and it was of the participant's volition to establish contact regarding their interest in participating. Hence, the study is likely to have attracted individuals who were willing to reflect on their use of PE skills and who may be transitioning more adaptively into the EA period and possibly experiencing fewer challenges. Additionally, the study may have attracted participants who exhibited either highly positive or highly negative views of PE. Responses may not have been reflective of typical experiences of PE and the findings here may have been affected by biases. Importantly, the goal of this research was to provide insights into how PE programs can be further developed to promote sustainability of skill use, and both "best case" and "worst case" scenarios are relevant to this aim.

\subsection{Future directions}

The current study has provided valuable findings and initial insight into a topic with a limited research base. As such, hypotheses have been generated that future research may investigate in larger-scale quantitative studies, to contribute to a body of literature regarding the ways in which emerging adults utilise coping strategies acquired through wellbeing programs in schools. For example, it may be beneficial for future research to consider the effects of personality and personal characteristics in the use of PE skills in EA. It may be expected that personality characteristics, such as excessive worry and proneness to focus on negative emotions, may mean that those people appraise challenges as highly threatening and may perceive to have limited resources to cope effectively (Grant \& Langan-Fox, 2006), whereas people who generally tend to have a positive outlook and predominantly experience positive emotions may perceive events as challenges and believe they have sufficient coping resources to mitigate the challenges, which links to the findings of this study. The study indicates that PE programs could look to focus on assessing personal coping styles to utilise existing abilities, teaching staff as positive role models, self-efficacy to build confidence in using PE skills beyond school years, fostering intrinsic motivation, and experiential learning techniques. Finally, participants responded favourably to ongoing access to resources, and the school might make resources available through online channels (e.g., websites, social media), as recommended by participants, and also given internet use is highly ubiquitous among this age group.

\subsection{Conclusions}

Overall, the current study contributed to informing the ways in which young people who are transitioning through the EA period utilise PE skills to mitigate challenges. The current study findings indicated that young people tend to use PE skills that have been acquired in secondary school, mainly as a function of valuing the skills and due to the positive influences of others. 
However, the participants indicated that a range of other PE skills are not being utilised, mainly due to difficulties in generalising the skills and applying them to new challenges, not giving high value to the skills, having limited understanding of the purpose of some skills, insufficient external reinforcers, and a perceived lack of engaging teaching methods. Hence, there is evidence from the study that coping strategies learned in PE could be relevant beyond secondary school, but the challenge remains of how to leverage this potential. These findings are valuable in guiding future research to investigate individual differences in successful use of positive education programs and in particular its capacity to continue to support students once they have completed their studies.

\section{Acknowledgements}

Thank you to the Geelong Grammar School graduates who generously contributed their time and insights to this project.

\section{Conflict of interest statement}

Meredith O'Connor and Erin Hoare were employees of Geelong Grammar School during this research project $(\mathrm{MO})$ and drafting of publication $(\mathrm{EH})$.

\section{Authors}

Nina Stevanovic

University of Melbourne

n.stevanovic0302@gmail.com

\section{Erin Hoare}

Geelong Grammar School

Vicki Mckenzie

University of Melbourne

Meredith O'Connor

University of Melbourne

\section{Publishing Timeline}

Received 29 June 2017

Accepted 8 November 2017

Published 12 December 2017

\section{References}

Arnett, J. J. (2000). Emerging adulthood: A theory of development from the late teens through the twenties. American Psychologist, 55(5), 469. https://doi.org/10.1037/0003-066X.55.5.469

Arnett, J. J. (2006). Emerging adulthood: Understanding the new way of coming of age. In J. Arnett \& J. Tanner (Eds.), Emerging adults in America: Coming of age in the 21st century (pp. 3-20). Washington DC: American Psychological Association. https://doi.org/10.1093/acprof:oso/9780195309379.001.0001

Australian Bureau of Statistics. (2016). Marriages and divorces, Australia, 2015. (3310.0). Canberra, Australia.

Braun, V., \& Clarke, V. (2006). Using thematic analysis in psychology. Qualitative Research in Psychology, 3(2), 77-101. https://doi.org/10.1191/1478088706qp063oa

Brunwasser, S. M., Gillham, J. E., \& Kim, E. S. (2009). A meta-analytic review of the Penn Resiliency Program's effect on depressive symptoms. Journal of Consulting and Clinical Psychology, 77(6), 1042. https://doi.org/10.1037/a0017671 
Campbell, J., Quincy, C., Osserman, J., \& Pedersen, O. (2013). Coding in-depth semistructured interviews: Problems of unitization and intercoder reliability and agreement. Sociological Methods and Research, 42(3), 294-320. https://doi.org/10.1177/0049124113500475

Côté, J. (2006). Emerging adulthood as an institutionalized maratorium: Risks and benefits to identity formation. In J. J. Arnett \& J. I. Tanner (Eds.), Emerging adults in America: Coming of age in the 21st century (pp. 85-116). Washington DC: APA Books. https://doi.org/10.1037/11381-004

Eccles, J., Templeton, J., Barber, B., \& Stone, M. (2003). Adolescence and emerging adulthood: The critical passage ways to adulthood. In M. H. Bornstein, L. Davidson, C. L. M. Keyes, \& K. A. Moore (Eds.), Crosscurrents in contemporary psychology. Well-being: Positive development across the life course (pp. 383406). Mahwah, NJ: Lawrence Erlbaum Associates.

Eccles, J., \& Wigfield, A. (2002). Motivational beliefs, values, and goals. Annual Review of Psychology, 53, 109-132. https://doi.org/10.1146/annurev.psych.53.100901.135153

Freire, P. (1993). The pedagogy of the oppressed. New York, NY: Continuum.

Grant, S., \& Langan-Fox, J. (2006). Occupational stress, coping and strain: The combined/interactive effect of the Big Five traits. Personality and Individual Differences, 41(4), 719-732. https://doi.org/10.1016/j.paid.2006.03.008

Harlow, L., Mitchell, K., Fitts, S., \& Saxon, S. (1999). Psycho-existential distress and problem behaviors: Gender, subsample, and longitudinal tests. Journal of Applied Biobehavioral Research, 4(2), 111-138. https://doi.org/10.1111/j.1751-9861.1999.tb00059.x

Hayes, A., Qu, L., Weston, R., \& Gray, M. (2010). Families then and now: 1980-2010. Journal of the Home Economics Institute of Australia, 17(2), 33.

Hyland, T. (2015). The limits of mindfulness: Emerging issues for education. British Journal of Educational Studies, 63(3), 1-21. https://doi.org/10.1080/00071005.2015.1051946

Johnson, M. L., Taasoobshirazi, G., Kestler, J. L., \& Cordova, J. R. (2014). Models and messengers of resilience: A theoretical model of college students' resilience, regulatory strategy use, and academic achievement. Educational Psychology, 35(7), 869-885. https://doi.org/10.1080/01443410.2014.893560

Kessler, R., \& Walters, E. (1998). Epidemiology of DSM-III-R major depression and minor depression among adolescents and young adults in the National Comorbidity Survey. Depression and Anxiety, 7(1), 3-14. https://doi.org/10.1002/(SICI)1520-6394(1998)7:1<3::AID-DA2>3.0.CO;2-F

Kolb, A. Y., \& Kolb, D. A. (2008). The Learning Way: Meta-cognitive aspects of experiential learning. Simulation \& Gaming, 40(3), 297-327. https://doi.org/10.1177/1046878108325713

Mahmoud, J. S., Staten, R., Hall, L. A., \& Lennie, T. A. (2012). The relationship among young adult college students' depression, anxiety, stress, demographics, life satisfaction, and coping styles. Issues in Mental Health Nursing, 33(3), 149-156. https://doi.org/10.3109/01612840.2011.632708

Masten, A. S. (2001). Ordinary magic: Resilience processes in development. American Psychologist, 56(3), 227-238. https://doi.org/10.1037/0003-066X.56.3.227

Masten, A., Obradović, J., \& Burt, K. (2006). Resilience in emerging adulthood: Developmental perspectives on continuity and transformation (pp. 173-190). Washington, DC: American Psychological Association.

McGorry, P. (2013). Prevention, innovation and implementation science in mental health: The next wave of reform. British Journal of Psychiatry, 202(s54). https://doi.org/10.1192/bjp.bp.112.119222

Moos, R. H., \& Holahan, C. J. (2003). Dispositional and contextual perspectives on coping: Toward an integrative framework. Journal of Clinical Psychology, 59(12), 1387-1403. https://doi.org/10.1002/jclp.10229

Norrish, J. M., Williams, P., O'Connor, M., \& Robinson, J. (2013). An applied framework for Positive Education. International Journal of Wellbeing, 3(2), 147-161.

O'Connor, M., \& Cameron, G. (2017). The Geelong Grammar positive psychology experience: Social and emotional learning in Australia and the Asia-Pacific (pp. 353-370). Singapore: Springer.

https://doi.org/10.1007/978-981-10-3394-0 19

O'Connor, M., Sanson, A. V., Toumbourou, J. W., Hawkins, M. T., Letcher, P., Williams, P., . . \& Arnett, J. J. (2014). Positive development and resilience in emerging adulthood. https://doi.org/10.1093/oxfordhb/9780199795574.013.19 
Ory, M. G., Lee Smith, M., Mier, N., \& Wernicke, M. M. (2010). The science of sustaining health behavior change: The health maintenance consortium. American Journal of Health Behavior, 34(6), 647-659. https://doi.org/10.5993/AJHB.34.6.2

Ryan, R. M. (1995). Psychological needs and the facilitation of integrative processes. Journal of Personality, 63(3), 397-427. https://doi.org/10.1111/j.1467-6494.1995.tb00501.x

Ryan, R. M., \& Deci, E. L. (2000a). Self-determination theory and the facilitation of intrinsic motivation, social development, and well-being. American Psychologist, 55(1), 68-78. https://doi.org/10.1037//0003$\underline{066 X .55 .1 .68}$

Ryan, R. M., \& Deci, E. L. (2000b). Intrinsic and extrinsic motivations: Classic definitions and new directions. Contemporary Educational Psychology, 25(1), 54-67. https://doi.org/10.1006/ceps.1999.1020

Schulenberg, J., Sameroff, A., \& Cicchetti, D. (2004). The transition to adulthood as a critical juncture in the course of psychopathology and mental health. Development and Psychopathology, 16(4), 799-806. https://doi.org/10.1017/S0954579404040015

Schulenberg, J., \& Zarrett, N. (2006). Mental health druing emerging adulthood: Continuity and discontinuity in courses, causes, and functions. In J. Arnett \& J. Tanner (Eds.), Advances in emerging adulthood (pp. 135-172). Washington, DC: American Psychological Association.

Seligman, M., Ernst, R., Gillham, J., Reivich, K., \& Linkins, M. (2009). Positive education: Positive psychology and classroom interventions. Oxford Review of Education, 35(3), 293-311. https://doi.org/10.1080/03054980902934563

Tugade, M. M., \& Fredrickson, B. L. (2006). Regulation of positive emotions: Emotion regulation strategies that promote resilience. Journal of Happiness Studies, 8(3), 311-333. https://doi.org/10.1007/s10902-006-9015-4

Vella-Brodrick, D. A., Rickard, N. S., \& Chin, T.-C. (2014). An evaluation of positive education at Geelong Grammar School: A snapshot of 2013. Melbourne, Australia: The University of Melbourne.

Vuong, M., Brown-Welty, S., \& Tracz, S. (2010). The effects of self-efficacy on academic success of firstgeneration college sophomore students. Journal of College Student Development, 51(1), 50-64. https://doi.org/10.1353/csd.0.0109

Waters, L. (2012). A review of school-based positive psychology interventions. The Australian Educational and Developmental Psychologist, 28(02), 75-90. https://doi.org/10.1375/aedp.28.2.75

World Health Organization. (2014). Global status report on noncommunicable diseases 2014: Author. 